Conclusion Ambulatory arterial stiffness index was correlated with tumour necrosis factor-a. Inflammation was relevant to the development of arterial stiffness in prehypertensives.

\title{
[gw22-e0535] IMPACT OF TUMOUR NECROSIS FACTOR-A ON AMBULATORY ARTERIAL STIFFNESS INDEX IN PREHYPERTENSIVES
}

Li Jun, Lu Fanghong, Zhao Yingxin, Liu Zhendong Institute of Basic Medicine Shandong Academy of Medical Sciences, Jinan, China

\subsection{6/heartjnl-2011-300867.581}

Objective To investigate the impact of tumour necrosis factor-a on ambulatory arterial stiffness index in prehypertensives.

Methods One hundred normotensives and one hundred and five prehypertensives were recruited, while one hundred and ten hypertensives were enrolled. $24 \mathrm{~h}$ ambulatory blood pressure monitoring (ABPM) was carried out in the three groups, respectively, and ambulatory arterial stiffness index (AASI) was computed. Tumour necrosis factor-a (TNF-a) was measured using radioimmunity kits.

Results Tumour necrosis factor-a and a mbulatory arterial stiffness index in prehypertensives $(44.21 \pm 9.81 \mathrm{pg} / \mathrm{ml}, 0.42 \pm 0.13)$, were higher than that in normotensives $(26.91 \pm 12.35 \mathrm{pg} /$ $\mathrm{ml}, 0.36 \pm 0.15)$, while lower than that in hypertensives $(59.74 \pm 23.38 \mathrm{pg} / \mathrm{ml}, 0.49 \pm 0.12)$. Pearson correlation analysis showed that the level of tumour necrosis factor-a was positively correlated with ambulatory arterial stiffness index in prehypertensives $(r=0.513, p<0.01)$. Multiple linear stepwise regression analysis showed that ambulatory arterial stiffness index still correlated with tumour necrosis factor-a $(b=0.272$, $\mathrm{p}<0.01)$. 